\title{
Hyperglycemia in pregnancy: prevalence, impact, and management challenges
}

\author{
This article was published in the following Dove Press journal: \\ International Journal of Women's Health \\ 20 September 2016 \\ Number of times this article has been viewed
}

\author{
Diane Farrar \\ Bradford Institute for Health \\ Research, Maternal and Child Health, \\ Bradford, UK
}

\begin{abstract}
Gestational diabetes mellitus (GDM) is one of the most common medical conditions in pregnancy, and the prevalence is growing with increasing rates of women of advanced age becoming pregnant and the increasing prevalence of maternal obesity and inactivity. GDM is associated with an increased risk of maternal and infant short- and long-term ill-health. There is a positive linear association between increasing maternal glucose at oral glucose tolerance testing and risk of important perinatal outcomes, including cesarean section, large for gestational age, and infant adiposity. A "step-up" approach, where diet and lifestyle information is provided followed by pharmacological interventions as required to control and reduce hyperglycemia, is effective at reducing the risk of macrosomia, but treatment of GDM will increase demand on health services. There is limited evidence to suggest which identification strategy is best or what thresholds should be used to diagnose GDM or what the effects of different diagnostic strategies have on short- or long-term maternal and offspring outcomes. Trials of interventions in pregnancy aimed at preventing GDM have not demonstrated a benefit; therefore, trials are needed to evaluate interventions aimed at optimizing the health of all women of childbearing age, outside of pregnancy. A consistent, evidence-based, sustained approach to supporting women to live healthily, including the achievement of a normal body mass index before and after pregnancy, is urgently needed.
\end{abstract}

Keywords: gestational diabetes, adverse perinatal outcomes, screening, glucose threshold criteria

\section{Introduction}

Normal pregnancy is associated with insulin resistance similar to that found in type 2 diabetes. This physiological resistance to insulin action during pregnancy becomes more apparent in the second trimester, and insulin resistance increases progressively to term. Changes in insulin resistance occur to facilitate transport of glucose across the placenta to ensure normal fetal growth and development. Transfer of glucose across the placenta stimulates fetal pancreatic insulin secretion, and insulin acts as an essential growth hormone. If resistance to maternal insulin action becomes too pronounced, maternal hyperglycemia occurs and gestational diabetes mellitus (GDM) may be diagnosed.

GDM is associated with an increased risk of adverse perinatal outcomes, including large for gestational age (LGA), macrosomia (usually defined as birthweight $>4 \mathrm{~kg}$ or $>4.5 \mathrm{~kg}$ ), induction of labor, and cesarean section. ${ }^{1}$ There is also growing evidence that GDM is associated with an increased risk of long-term ill-health outcomes in the mother (type 2 diabetes and cardiovascular disease) ${ }^{2,3}$ and offspring (obesity and associated cardiometabolic risk). ${ }^{4,5}$
Bradford Institute for Health Research,

Bradford Teaching Hospitals NHS

Foundation Trust, Duckworth Lane,

Bradford BD9 6RJ, UK

Tel +44 I2743834I6

Email diane.farrar@bthft.nhs.uk 


\section{What is GDM}

GDM is defined as carbohydrate intolerance resulting in hyperglycemia of variable severity with onset or first recognition during pregnancy, ${ }^{6}$ GDM defined in this way includes women with undiagnosed preexisting diabetes, as well as women with first-onset hyperglycemia during pregnancy. The confirmation of whether a woman has preexisting (overt) diabetes or GDM can only be reliably made following pregnancy (as described in the "Care following birth" section). In the past, less severe GDM was referred to as impaired glucose tolerance and more severe as GDM; now the whole higher end of the glucose spectrum is more simply referred to as GDM.

GDM is the most common metabolic disorder of pregnancy; rates vary depending on population characteristics (eg, maternal age, ethnicity, or body mass index [BMI]) and screening and diagnostic strategies, including glucose thresholds used (Tables 1 and 2). ${ }^{7-9}$

\section{Identification of GDM: screening and testing}

Screening is the process of identifying women who are at higher risk of GDM compared with the general population of pregnant women. Once identified, those women can consider further tests, and health care providers can offer interventions that may improve their health and/or that of their infant. A screening program should offer more benefits than harm, at a reasonable cost to the health service. A screening/diagnostic test is any approach used to gather clinical information for the purpose of making a clinical decision and is a process that helps determine the presence or absence of a condition. For GDM, the oral glucose tolerance test (OGTT) is generally the diagnostic test of choice; this test is usually administered between 24 and 28 weeks of gestation. A plasma blood sample is obtained following an overnight fast and then a $75 \mathrm{~g}$ or $100 \mathrm{~g}$ glucose load is given and further plasma blood sample is obtained after 1, 2, or 3 hours. GDM is diagnosed (depending on the criteria used) if one, two, or more glucose levels are equaled or exceeded. A recent systematic review identified only one trial (with 248 women) examining the effectiveness of the $75 \mathrm{~g}$ compared with the $100 \mathrm{~g}$ OGTT; this trial reported that more women were diagnosed with GDM using the $75 \mathrm{~g}$ OGTT; other important outcomes were not reported. Other methods to diagnose GDM have been evaluated, eg, using jelly beans, chocolate bars, and meals as the "challenge" in place of the more usual glucose load of the OGTT; however, studies are few and include few women and consequently there is no clear evidence to suggest which test is superior. ${ }^{10}$

The American College of Obstetricians and Gynecologists $(\mathrm{ACOG})^{11}$ and UK National Institute for Health and Care Excellence (NICE) recommend that women who have had GDM in a previous pregnancy should be offered diagnostic testing (ACOG also recommends early testing in obese women or women with impaired glucose metabolism) as early as possible after pregnancy booking (in either the first or second trimester) to identify undiagnosed type 2 diabetes. The Australasian Diabetes in Pregnancy Society (ADIPS) recommends risk factor assessment in early pregnancy; risk factors are ranked by severity and either one "high" risk factor or two "moderate" risk factors are needed before an OGTT is offered (Table 2). ${ }^{12}$

For all women not tested in early pregnancy and those women with a negative early screen, the $\mathrm{ACOG}^{11}$ suggests that screening for GDM should take place at 24-28 weeks by assessment of medical history, clinical risk factors, or a laboratory screening test (Table 2). The UK NICE

Table I Current and previous criteria recommended to diagnose GDM (plasma glucose levels in $\mathrm{mmol} / \mathrm{L}$ )

\begin{tabular}{|c|c|c|c|c|}
\hline Criteria & Fasting & I hour postload & 2 hours postload & 3 hours postload \\
\hline \multicolumn{5}{|l|}{75 g OGTT (plasma glucose) } \\
\hline $\begin{array}{l}\operatorname{IADPSG}^{\mathrm{a}, 19}(2010), \operatorname{ADIPS}^{12}(2013) \text {, } \\
\text { and WHO } \mathrm{WH}^{\mathrm{a}, 17}(2013)\end{array}$ & $\geq 5.1$ & $\geq 10.0$ & $\geq 8.5$ & - \\
\hline $\mathrm{WHO}^{\mathrm{a}, 46}(1999)$ & $\geq 6.1$ & - & $\geq 7.8$ & - \\
\hline $\operatorname{ADA}^{\mathrm{a}, 47}(2006)$ & $\geq 5.3$ & $\geq 10.0$ & $\geq 8.6$ & - \\
\hline ADIPS $^{\mathrm{a}, 48}(1998)$ & $\geq 5.5$ & - & $\geq 8.0$ & - \\
\hline \multicolumn{5}{|l|}{$100 \mathrm{~g}$ OGTT (plasma or serum glucose) } \\
\hline ACOGb,11/C\&C (20I3) & $\geq 5.3$ & $\geq 10.0$ & $\geq 8.6$ & $\geq 7.8$ \\
\hline NDDG ${ }^{\mathrm{b}, 6}(1979)$ & $\geq 5.8$ & $\geq 10.6$ & $\geq 9.2$ & $\geq 8.0$ \\
\hline O’Sullivan and Mahan ${ }^{6,49}(1964)$ & $\geq 5.0$ & $\geq 9.2$ & $\geq 8.1$ & $\geq 6.9$ \\
\hline
\end{tabular}

Notes: ane threshold should be met or exceeded for GDM to be diagnosed. ${ }^{\top} T$ wo thresholds should be met or exceeded for GDM to be diagnosed.

Abbreviations: ACOG, American College of Obstetricians and Gynecologists; ADA, American Diabetes Association; ADIPS, Australasian Diabetes in Pregnancy Society; C\&C, Carpenter and Coustan; GDM, gestational diabetes mellitus; IADPSG, International Association of Diabetes in Pregnancy study Groups; NDDG, National Diabetes Data Group; OGTT, oral glucose tolerance test; WHO, World Health Organization. 
Table 2 Recommended risk factors by organization

\begin{tabular}{|c|c|}
\hline Agency & Nature of screening strategy \\
\hline $\mathrm{NICE}^{16}$ (UK) & $\begin{array}{l}\text { Offer OGTT only to women with at least one of the following: } \\
\text { - } \mathrm{BMI} \geq 30 \mathrm{~kg} / \mathrm{m}^{2} \\
\text { - Previous macrosomic baby }(>4.5 \mathrm{~kg}) \\
\text { - Previous GDM } \\
\text { - Family history of diabetes } \\
\text { - Family minority ethnic origin with a high prevalence of diabetes }\end{array}$ \\
\hline $\mathrm{ADA}^{15}$ & $\begin{array}{l}\text { Testing at first antenatal visit should be undertaken to identify undiagnosed type } 2 \text { diabetes (universal OGTT testing } \\
\text { is recommended at } 24-28 \text { weeks) in all pregnant women who are overweight (BMI } \geq 25 \mathrm{~kg} / \mathrm{m}^{2} \text { ) and have additional } \\
\text { risk factors: } \\
\text { - Physical inactivity } \\
\text { - First-degree relative with diabetes } \\
\text { - High-risk race/ethnicity (eg, African-American, Latino, Native American, Asian-American, and Pacific Islander) } \\
\text { - Women who delivered a baby weighing }>4 \mathrm{~kg} \text { or were diagnosed with GDM } \\
\text { - Hypertension ( } \geq I 40 / 90 \mathrm{mmHg} \text { or on therapy for hypertension) } \\
\text { - HDL cholesterol level }<35 \mathrm{mg} / \mathrm{dL}(0.90 \mathrm{mmol} / \mathrm{L} \text { ) and/or a triglyceride level }>250 \mathrm{mg} / \mathrm{dL} \text { ( } 2.82 \mathrm{mmol} / \mathrm{L} \text { ) } \\
\text { - Women with polycystic ovarian syndrome } \\
\text { - AIC } \geq 5.7 \% \text {, IGT, or IFG on previous testing } \\
\text { - Other clinical conditions associated with insulin resistance (eg, severe obesity and acanthosis nigricans) } \\
\text { - History of CVD }\end{array}$ \\
\hline ADIPS (Nankervis et al ${ }^{12}$ ) & $\begin{array}{l}\text { Women who are from a high-risk ethnic background or have a BMI of } 25-35 \mathrm{~kg} / \mathrm{m}^{2} \text { as their only risk factor should } \\
\text { be considered "moderate risk" and should initially be screened with either a random or a fasting glucose test in } \\
\text { early pregnancy, followed by an OGTT if clinically indicated. ADIPS suggests that the thresholds for further action } \\
\text { are not clear currently and clinical judgment should be exercised. } \\
\text { Women at "high risk" of GDM (one high-risk factor or two moderate-risk factors) should be offered a } 75 \mathrm{~g} \text { OGTT, } \\
\text { with venous plasma samples taken: fasting, I hour and } 2 \text { hours at the first opportunity after conception. Women at } \\
\text { moderate or high risk with normal glucose should be offered an OGTT at } 24-28 \text { weeks: } \\
\text { - Moderate-risk factors for GDM } \\
\text { - Ethnicity: Asian, Indian subcontinent, Aboriginal, Torres Strait Islander, Pacific Islander, Maori, Middle Eastern, } \\
\text { and non-white African } \\
\text { - BMI: } 25-35 \mathrm{~kg} / \mathrm{m}^{2} \\
\text { - High-risk factors for GDM } \\
\text { - Previous GDM } \\
\text { - Previously elevated blood glucose level } \\
\text { - Maternal age } \geq 40 \text { years } \\
\text { - Family history of DM (first-degree relative with diabetes or a sister with GDM) } \\
\text { - BMI }>35 \mathrm{~kg} / \mathrm{m}^{2} \\
\text { - Previous macrosomia (BW }>4,500 \mathrm{~g} \text { or }>90 \text { th percentile) } \\
\text { - Polycystic ovarian syndrome } \\
\text { - Medications: corticosteroids, antipsychotics }\end{array}$ \\
\hline
\end{tabular}

Abbreviations: ADA, American Diabetes Association; ADIPS, Australasian Diabetes in Pregnancy Society; AIC, glycated hemoglobin; BMI, body mass index; BW, birth weight; CVD, cardiovascular disease; DM, diabetes mellitus; GDM, gestational diabetes mellitus; HDL, high-density lipoprotein; IFG, impaired fasting glucose; IGT, impaired glucose tolerance; OGTT, oral glucose tolerance test; WHO, World Health Organization.

recommends that the risk of GDM be assessed in all women (not previously identified as having type 2 diabetes) using maternal characteristics or risk factors. If a woman has one or more of these risk factors (family history of diabetes; ethnicity with a high prevalence of diabetes; South Asian, black, or Middle Eastern ethnicity; previous history of having a macrosomic baby; BMI $\left(\mathrm{kg} / \mathrm{m}^{2}\right) \geq 30$, or previous GDM), diagnostic testing should be offered at 26-28 weeks of gestation. ${ }^{13}$ The ADIPS recommends all women not identified in early pregnancy as having hyperglycemia should be offered a $75 \mathrm{~g}$ OGTT at 24-28 weeks (Table 2). ${ }^{12}$
The performance of risk factors in identifying women who will develop GDM is poor; however, when a risk factor identifies true positives well (women with GDM; has high sensitivity) it poorly identifies true negatives (women without GDM; has low specificity) and when a risk factor identifies true negatives well (high specificity) it poorly identifies true positives (low sensitivity), consequently, to identify most women with GDM, most women may need to be tested. ${ }^{14}$ The $50 \mathrm{~g}$ oral glucose challenge test (OGCT), similarly to risk factors, can be used to identify women at high risk of GDM; no overnight fast is required (like the 
$75 \mathrm{~g}$ or $100 \mathrm{~g}$ OGTT), rather a $50 \mathrm{~g}$ glucose load is given and then an hour later a plasma blood sample is obtained; if a glucose threshold is exceeded, an OGTT will be offered. The American Diabetes Association (ADA) recommends the glucose threshold of $\geq 7.8 \mathrm{mmol} / \mathrm{L},{ }^{15}$ though $>7.2 \mathrm{mmol} / \mathrm{L}$ and $\geq 7.5 \mathrm{mmol} / \mathrm{L}$ are also used. The ACOG suggests that there is insufficient evidence to support one threshold over another; for that reason, care providers should select one threshold and use it consistently in their population. ${ }^{11}$ The UK NICE $^{16}$ and the ADIPS ${ }^{12}$ evaluated the evidence examining the performance of the $50 \mathrm{~g}$ OGCT in identifying women who will develop GDM, reporting that the performance of the OGCT is equivalent to that of risk factors, but it is more costly, and that the OGCT lacks both sensitivity and specificity, respectively; consequently, the $50 \mathrm{~g}$ OGCT has not been recommended as a screening method in the UK or Australasia. ${ }^{12,16}$ Unlike the ACOG and the UK NICE, the International Association of Diabetes in Pregnancy Study Groups (IADPSG; indorsed recently by the World Health Organization [WHO], ${ }^{17}$ ADIPS, ${ }^{12}$ and the International Federation of Gynecology and Obstetrics ${ }^{18}$ ) do not advocate screening women for "high-risk" status (either by $50 \mathrm{~g}$ OGCT or risk factors) and recommend that all women not previously identified as having type 2 diabetes are offered a diagnostic test at 24-28 weeks of gestation (the $75 \mathrm{~g}$ OGTT). ${ }^{19}$

The approach of offering testing to only women with a risk factor or positive OGCT (NICE/ACOG or "two-step" approach/selective testing) may miss some women with hyperglycemia who may benefit from treatment; the latter approach (the IADPSG or "one-step" approach/universal testing) may result in unnecessary testing of women at low risk, but more women will be identified and therefore more may benefit from treatment, though it is unclear which screening and testing approach is most clinically helpful or cost-effective. ${ }^{10,14,20}$ In response to the lack of evidence supporting one approach over another, the ADA recommends using either the one- or two-step approach (two step using the $50 \mathrm{~g}$ OGCT) but suggests that a consistent approach to testing would be beneficial. ${ }^{15}$

Recent studies ${ }^{7,21}$ show a graded positive linear association between maternal glucose and risk of important perinatal adverse outcomes, including cesarean section, LGA, and infant adiposity. This means that for each increase in glucose (at OGTT), there is an increase in risk of adverse outcomes; consequently, there is no clear clinical threshold at which risk increases significantly, which would indicate a threshold to diagnose GDM and offer treatment. Therefore, how are glucose thresholds identified to diagnose GDM? First, a decision on what the aim of GDM diagnosis is needs to be made. Previously, the aim was to identify women at risk of future type 2 diabetes, ${ }^{22}$ more recently, the need to reduce the risk of associated perinatal adverse outcomes was recognized and it is known from treatment trials that controlling and reducing hyperglycemia reduce the risk of some of these perinatal outcomes ${ }^{23,24}$ and this is important to both women and clinicians. ${ }^{25}$ Importantly, there is now evidence that the offspring of women who have had GDM are at increased risk of future obesity and cardiometabolic ill-health. Reducing long-term obesity risk is key for the future health of the population and one way to potentially achieve this is by treating women with hyperglycemia during pregnancy.

The IADPSG, therefore, devised criteria aimed at identifying infants of women with GDM at increased risk of long-term future obesity and cardiometabolic ill-health through their association with the perinatal outcomes such as high cord C-peptide (surrogate for insulin), LGA, and high infant adiposity. By treating these women and reducing hyperglycemia, the risk of these adverse perinatal outcomes may be reduced along with subsequent long-term risks. ${ }^{19}$

The IADPSG derived their new threshold criteria using data from the Hyperglycemia and Adverse Pregnancy Outcomes study. ${ }^{21}$ Hyperglycemia and Adverse Pregnancy Outcomes is an observational study showing graded linear associations between maternal glucose and adverse outcomes (described earlier). ${ }^{21}$ Because no clear clinical thresholds were identified, the IADPSG derived thresholds based on the glucose values at which the odds ratios reached 1.75 above mean glucose values, for birthweight greater than the 90th percentile, percent infant body fat (based on skinfolds) greater than the 90th percentile, and concentration of cord C-peptide greater than the 90th percentile. The IADPSGrecommended thresholds are as follows: plasma glucose levels of $5.1 \mathrm{mmol} / \mathrm{L}, 10 \mathrm{mmol} / \mathrm{L}$, and $8.5 \mathrm{mmol} / \mathrm{L}$ for fasting, 1 hour, and 2 hour postload (75 g OGTT), respectively. GDM is diagnosed if one or more of these thresholds are equaled or exceeded. Although somewhat arbitrary and derived from just one study, these thresholds have been recently endorsed by the $\mathrm{WHO}^{17}$ and others. ${ }^{12}$ The UK NICE, however, recommends different thresholds (fasting: $5.6 \mathrm{mmol} / \mathrm{L}$ and 2 hours postload: $7.8 \mathrm{mmol} / \mathrm{L}$ [75 g OGTT]) but does not make clear how they were derived. ${ }^{13,16}$ The ACOG conversely recommends using either the Carpenter and Coustan or the National Diabetes Data Group criteria thresholds. ${ }^{11}$

Given the linear association between glucose and risk of adverse outcomes, it is possible that identifying and 
treating women at lower glucose levels than were previously recommended will result in a reduction in risk of these outcomes because more women will be identified and treated. The clinical effectiveness of the IADPSG-recommended criteria, however, is inferred from treatment trials that show a reduction in risk of LGA and macrosomia in women identified using higher glucose level thresholds, whether treating these women influences long-term health is unknown and that is a possible reason for the lack of uniformity in recommendations from international institutions such as the WHO, UK NICE, ADA, ADIPS, and ACOG. This absence of evidence and variation in recommended identification approaches has led to calls for trials investigating the application of different glucose thresholds for GDM diagnosis on maternal and offspring short- and long-term health outcomes.

\section{Prevalence}

Whether all, or only high-risk women, are tested, what glucose load $(75 \mathrm{~g} / 100 \mathrm{~g})$ is administered as part of the OGTT, what proportion of women have risk factors that predispose to GDM, and what glucose threshold criteria are used to diagnose GDM will all influence the prevalence of GDM. As an example of these influences, Table 3 shows the prevalence of GDM reported in different locations in the UK and the Republic of Ireland. Prevalence varies from 1.1\% in 1980 in Leicester using the WHO 1980 criteria (selective testing of only high-risk women, using higher glucose thresholds than IADPSG) to $24.3 \%$ in 2012 in Manchester using the IADPSG criteria (universal offer of testing within an observational study). A recent study estimated that globally in 2013, 21.4 million out of an estimated 127.1 million live births to women aged 20-49 years (crude prevalence, 16.9\%; age-standardized prevalence, $14.8 \%$ ) were affected by GDM. ${ }^{26}$ Prevalence increases markedly in women over the age of 40 years and differs by region, with the majority of women with hyperglycemia residing in low- to middle-income countries, eg, Southeast Asia (Bangladesh, India, and Sri Lanka) has the highest crude prevalence (23.1\%) and Western Pacific (Australia, the People's Republic of China, Hong Kong, Japan, Malaysia, Singapore, Thailand, and Vietnam) has the lowest $(11.8 \%)$; there is, however, also wide variation in reported prevalences for countries within these regions. ${ }^{26}$

Identifying greater numbers of women with GDM clearly has resource implications for care providers (but identifying more women could reduce the risk of adverse outcomes) and this is likely to influence whether a particular approach to the identification of women with GDM is followed. The large numbers of women with hyperglycemia in low- to middle-income countries are concerning as these countries may be the least well equipped to provide interventions to reduce associated risks, and socioeconomic influences may further disadvantage affected women and infants. Similarly, subgroups of socially deprived women in higher income countries may respond less well to intervention from health care providers compared with their socially advantaged counterparts; consequently, educational and support services should be tailored to the differing needs of these groups of women. ${ }^{26,27}$

Table 3 Prevalence of GDM in different locations in the UK and using different diagnostic criteria

\begin{tabular}{|c|c|c|c|c|c|c|}
\hline First author & $\begin{array}{l}\text { Publication } \\
\text { year }\end{array}$ & Location & $\begin{array}{l}\text { GDM diagnostic } \\
\text { criteria }\end{array}$ & $\begin{array}{l}\text { Number of } \\
\text { women included }\end{array}$ & $\begin{array}{l}\text { Number } \\
\text { with GDM }\end{array}$ & $\begin{array}{l}\text { Prevalence } \\
\text { of GDM (\%) }\end{array}$ \\
\hline \multirow[t]{2}{*}{ Ali et al ${ }^{50}$} & 2013 & Dublin & NDDG & 1,375 & 139 & 10.1 \\
\hline & & Dublin & IADPSG & 1,679 & 221 & 13.2 \\
\hline Dornhorst et $\mathrm{al}^{51}$ & 1992 & London (St Mary's) & Reported in paper ${ }^{a}$ & 11,035 & 170 & 1.5 \\
\hline Gregory et al ${ }^{40}$ & 1998 & Cambridge & WHO 1980 & 3,316 & 67 & 2.0 \\
\hline Griffin et al ${ }^{52}$ & 2000 & Dublin & NDDG & 1,299 & 35 & 2.7 \\
\hline Janghorbani et $\mathrm{al}^{53}$ & 2006 & Plymouth & WHO 1980 & 4,942 & 90 & 1.8 \\
\hline \multirow[t]{2}{*}{ Khalifeh et a $\left.\right|^{54}$} & 2014 & Dublin & WHO 1999 & 68,494 & 888 & 1.2 \\
\hline & & Dublin & WHO 1999 & 112,138 & 2,016 & 1.8 \\
\hline Koukkou et al ${ }^{55}$ & 1995 & London (St Thomas') & EASD $^{b}$ & 6,887 & 136 & 2.0 \\
\hline Makgoba et al ${ }^{56}$ & 2012 & London (St Mary's) & Varied $^{c}$ & 174,320 & 1,688 & 1.0 \\
\hline \multirow[t]{2}{*}{ Sacks et al ${ }^{57}$} & 2012 & Manchester & IADPSG & 2,376 & 577 & 24.3 \\
\hline & & Belfast & IADPSG & $|, 67|$ & 286 & 17.1 \\
\hline Samanta et $\mathrm{al}^{58}$ & 1989 & Leicester & WHO 1980 & 12,005 & 128 & 1.1 \\
\hline
\end{tabular}

Notes: WHO either 1980 or 1999 criteria depending on year data were generated. ${ }^{a} \mathrm{All}$ women without preexisting diabetes screened at booking and then those with risk factors were rescreened using modified O'Sullivan screening test, which was a $50 \mathrm{~g}$ OGCT followed by OGTT if level $>7.8 \mathrm{mmol} / \mathrm{L}$; GDM was diagnosed with 3-hour $100 \mathrm{~g}$ OGTT if AUC $\geq 4.3$ units. 'EASD criteria and $75 \mathrm{~g}$ OGTT used, GDM diagnosed if 2-hour $>9 \mathrm{mmol} / \mathrm{L}$. 'Only primiparous women included. No "common" screening test was used, as pregnancies were included from 1998 and 2000 and different criteria could have been used.

Abbreviations: EASD, European Association for the Study of Diabetes; GDM, gestational diabetes mellitus; IADPSG, International Association of Diabetes in Pregnancy study Groups; NDDG, National Diabetes Data Group; OGTT, oral glucose tolerance test; WHO, World Health Organization. 


\section{Treatment}

As discussed earlier, the treatment of GDM aims to reduce hyperglycemia and in turn reduces the risk of adverse outcomes. Diet and lifestyle modification/information is usually provided as first-line treatment and may in the future be more commonly the only treatment needed, if the widespread acceptance of lower GDM glucose threshold criteria occurs. Self-monitoring of glucose levels is recommended, particularly when oral hypoglycemics or insulin is required and levels are reviewed at each clinical visit.

Oral hypoglycemic agents (metformin and glyburide) present a possible alternative to injected insulin and seem effective as a first-line pharmacological intervention ${ }^{28}$ with the added benefit of perhaps being more acceptable to women, because metformin is taken orally as opposed to insulin that is injected. However, when packages of care compared with routine care were evaluated, up to half of women initially prescribed metformin require supplemental insulin. ${ }^{28-33}$ Metformin is also easier to store and can be kept at room temperature, whereas insulin requires refrigeration. However, metformin may cause gastrointestinal upset, ${ }^{34}$ and this may reduce compliance, prompting the need for supplemental insulin.

Treatments may also increase the risk of some adverse perinatal outcomes and concerns have been expressed about the potential for harm associated with the medicalization of pregnancy which predisposes caregivers toward an expectation of adverse outcomes and may increase morbidity due to increased interventions, including induction of labor. Metformin use has caused concern because it crosses the placenta and may therefore affect fetal development, though trials do not suggest that harms are increased when metformin is provided as first-line pharmacological treatment compared with insulin. ${ }^{28}$ Insulin and glyburide may cause maternal hypoglycemia, however, which may influence fetal wellbeing and could be harmful to women, though this risk must be balanced against the development of hyperglycemia and the increased risk of adverse perinatal outcomes.

Care is best provided by a team of clinicians, including nurse/midwife, obstetrician, diabetologist, dietician, and diabetic nurse specialist. Care should be individualized and dependent on the woman's views and needs and the degree of hyperglycemia, glucose control and presence/absence of other abnormalities (eg, LGA) and medical conditions (eg, hypertension). This individualized approach allows variation in the intensity of treatment (the step-up approach described earlier), eg, women with less severe hyperglycemia may require only diet and lifestyle modification and may require less intensive monitoring and antenatal visits than women with more severe hyperglycemia needing an additional pharmacological intervention to control hyperglycemia. ${ }^{14,35}$

Using the "step-up" approach ensures that interventions are only offered if required, resulting in less burden for the woman and care providers, which is particularly important given the increasing prevalence of GDM. The UK NICE now recommends women with GDM to be advised to eat a "healthy diet" during pregnancy and emphasize that foods with a low glycemic index should replace those with a high glycemic index and that women should walk 30 minutes a day to improve glucose control, though there is limited evidence of the effectiveness of this advice in improving outcomes.

As with care during pregnancy, care during labor should be individually tailored; women with less severe and wellcontrolled hyperglycemia and with a normally grown fetus may need less intensive monitoring or interventions such as induction, compared with women with severe less wellcontrolled hyperglycemia with an LGA fetus.

\section{Care following birth}

For most women, insulin resistance rapidly returns to normal following birth and therefore glucose-lowering treatments should be stopped if blood glucose levels decline and stay within normal parameters. Care of women following normalization of glucose levels is therefore the same as for any woman, though as with all women, care should be individualized. The care of infants of women who have had GDM depends on the infant's health and adaptation at birth. These infants are, however, at increased risk of hypoglycemia and as such, early, sustained, and adequate feeding is essential. All infants should be monitored (for signs of hypoglycemia and well-being), particularly in the first 24 hours following birth. Any infant asymptomatic of hypoglycemia should be allowed to demand feed and should not be subjected to invasive glucose level monitoring. Infants showing poor adaptation following birth or who show signs of hypoglycemia may need supplemental feeds and closer monitoring, including glucose estimation.

A proportion of women diagnosed with GDM will subsequently at postnatal testing be diagnosed with type 2 diabetes and a proportion of these women will have had diabetes preceding their pregnancy. Approximately $50 \%$ of women who have had GDM will develop type 2 diabetes within 5-10 years; this corresponds to a 7.5-fold increased risk over women who have not had GDM.,36 Women with GDM may not, however, attribute this risk to themselves, eg, in one study of women with GDM, $90 \%$ were aware of 
a link (between GDM and type 2 diabetes), but only $16 \%$ believed they themselves were at risk, this increased to $39 \%$ if they were told to assume they continued to live their current lifestyle. ${ }^{37}$ Therefore, women may plan to modify their lifestyle in an attempt to prevent future development of type 2 diabetes, whether this plan is realized, however, is unclear. Irrespective of women's intentions, health professionals have a responsibility to ensure women fully appreciate the risks and signs and symptoms of hyperglycemia.

The ACOG recommends postnatal screening at 6-12 weeks following birth, to identify continuing insulin resistance and hyperglycemia, and suggests that either a fasting plasma glucose (FPG) or the $75 \mathrm{~g}$, 2-hour OGTT is an appropriate test. ${ }^{11}$ The ADA recommends testing to be continued at three yearly intervals, whereas the ADIPS suggests that testing every $1-2$ years is sufficient and the UK NICE recommends yearly testing. The ADA does not recommend the HbA1c at early postnatal testing (which provides an estimate of average plasma glucose concentration over a period of weeks) because of the antenatal treatment to reduce hyperglycemia. This test could, however, be used at later follow-up and a result of $\geq 6.5 \%$ would indicate type 2 diabetes. ${ }^{15}$ Compared with the $75 \mathrm{~g}$ OGTT, the FPG is easier to perform, as no glucose load is given and no postload estimation is obtained (an FPG of $>7 \mathrm{mmol} / \mathrm{L}$ would indicate type 2 diabetes). The ADIPS recommends the $75 \mathrm{~g}$ OGTT at 6-12 weeks postnatal period, ${ }^{12}$ and the UK NICE recommends a fasting plasma assessment; ${ }^{13}$ however, the OGTT will also identify impaired glucose tolerance (2-hour postload sample $\geq 11.1 \mathrm{mmol} / \mathrm{L}$ ) as well as impaired fasting glucose so may be preferred and the test that adequately identifies abnormal postnatal glucose metabolism and insulin resistance may depend on population characteristics. ${ }^{38,39}$ However, rates of attendance at this postnatal assessment are low ${ }^{40,41}$ and may reflect women's perception of personal low risk as described earlier and also a lack of perceived importance placed on this condition by clinicians.

\section{Prevention}

Because of the increasing prevalence of GDM and its adverse influence on perinatal outcomes and associated long-term health outcomes, efforts have been made to evaluate interventions aimed at reducing the risk of GDM, particularly in high-risk obese women. One recent trial evaluated the provision of dietary and physical activity advice in addition to routine care during pregnancy. GDM rate did not differ between the two groups and although women assigned to the intervention compared with the control group gained less weight and were less adipose (sum of skinfolds); these differences were marginal ( $0.5 \mathrm{~kg}$ and $3 \mathrm{~mm}$, respectively) and arguably not clinically relevant. ${ }^{42} \mathrm{~A}$ further trial has evaluated metformin use in obese pregnant women (without diabetes) and risk of adverse perinatal outcomes. Although metformin is an effective treatment for GDM because it improves sensitivity to insulin, this trial failed to demonstrate any substantial effect on any outcome including the risk of GDM and high birthweight. ${ }^{43}$

The health of childbearing-age women is not just an issue confined to pregnancy. The lack of an effect of interventions in pregnancy designed to prevent GDM (described earlier) suggests that interventions to prevent GDM may be more successful if delivered outside of pregnancy when a more sustained approach to healthy living can take place. There is evidence that lifestyle interventions and metformin use in overweight people (outside of pregnancy) are effective interventions for reducing the risk of development of diabetes, with lifestyle interventions being more effective than metformin. ${ }^{44}$ Therefore, it may be that these interventions should be evaluated in young women prior to pregnancy. The UK NICE now recommends that women who have had GDM are offered lifestyle advice (including weight control, diet, and exercise) $)^{13}$ to reduce the risk of future type 2 diabetes, ${ }^{45}$ but this approach will not prevent initial GDM in a large and growing group of women.

\section{Conclusion}

Understanding that the risk of adverse outcomes increases with increasing glucose level (measured by the OGTT in pregnancy), across the whole glucose spectrum, is important for both women and those caring for them. To be able to target treatments at women most likely to benefit, however, a diagnosis of GDM needs to be made. The lack of clear clinical glucose thresholds has led to a variety of recommended criteria leading to global variation in practice, which is harmful to women and their infants.

There is limited evidence to support one approach for the identification of women with hyperglycemia/GDM over another. GDM treatment trials using older higher glucose thresholds (than the newer IADPSG-recommended criteria) show a reduction in risk of some perinatal outcomes; however, there are no trials that have used the IADPSG criteria, so the effect of using these criteria and short- or long-term outcomes is unknown and this has led to calls for trials evaluating different threshold criteria for GDM.

The increasing prevalence of obesity and obesity-related conditions including GDM is a public health concern. 
A sustained approach to supporting women to live healthily, including the achievement of a normal BMI before and after pregnancy is urgently needed. Large well-designed trials to evaluate lifestyle interventions to reduce BMI and risk of GDM for women of childbearing age are urgently required.

If we can find ways to hold back and even reduce the rising obesity epidemic in the general population and help women already overweight/obese achieve a normal weight, health improvements for the pregnant population will follow and these improvements may impact the future health of the whole population. Health professionals should provide women and their families with information and ensure that they understand what foods are beneficial and what foods to avoid and also what constitutes a "good" level of physical activity as well as provide signposting to other support services.

\section{Disclosure}

The author reports no conflicts of interest in this work.

\section{References}

1. Hartling L, Dryden DM, Guthrie A, Muise M, Vandermeer B, Donovan L. Benefits and harms of treating gestational diabetes mellitus: a systematic review and meta-analysis for the U.S. Preventive Services Task Force and the National Institutes of Health Office of Medical Applications of Research. Ann Intern Med. 2013;159(2): 123-129.

2. Bellamy L, Casas J-P, Hingorani AD, Williams D. Type 2 diabetes mellitus after gestational diabetes: a systematic review and metaanalysis. Lancet. 2009;373(9677):1773-1779.

3. Shah BR, Retnakaran R, Booth GL. Increased risk of cardiovascular disease in young women following gestational diabetes mellitus. Diabetes Care. 2008;31(8):1668-1669.

4. Boney CM, Verma A, Tucker R, Vohr BR. Metabolic syndrome in childhood: association with birth weight, maternal obesity, and gestational diabetes mellitus. Pediatrics. 2005;115(3):e290-e296.

5. Lawlor DA, Fraser A, Lindsay RS, et al. Association of existing diabetes, gestational diabetes and glycosuria in pregnancy with macrosomia and offspring body mass index, waist and fat mass in later childhood: findings from a prospective pregnancy cohort. Diabetologia. 2010;53(1):89-97.

6. National Diabetes Data Group. Classification and diagnosis of diabetes mellitus and other categories of glucose intolerance. Diabetes. 1979;28(12):1039-1057.

7. Farrar D, Fairley L, Santorelli G, et al. Association between hyperglycaemia and adverse perinatal outcomes in south Asian and white British women: analysis of data from the Born in Bradford cohort. Lancet Diabetes Endocrinol. 2015;3(10):795-804.

8. Avalos GE, Owens LA, Dunne F; ATLANTIC DIP Collaborators. Applying current screening tools for gestational diabetes mellitus to a European population: is it time for change? Diabetes Care. 2013;36(10): 3040-3044.

9. Ferrara A. Increasing prevalence of gestational diabetes mellitus: a public health perspective. Diabetes Care. 2007;30(suppl 2):S141-S146.

10. Farrar D, Medley N, Duley L, Lawlor D. Different strategies for diagnosing gestational diabetes to improve maternal and infant health. Cochrane Database Syst Rev. 2015;(1):CD007122.CD007122. pub3.

11. American College of Obstetricians and Gynecologists. Practice bulletin clinical management guidelines for obstetricians - gynecologists. Obstet Gynecol Clin North Am. 2013;122(2):406-416.
12. Nankervis A, McIntyre H, Moses R, et al. ADIPS Consensus Guidelines for the Testing and Diagnosis of Gestational Diabetes Mellitus in Australia; 2013. Available from: http://adips. org/downloads/ADIP S Consensus Guidelines GDM-03. 05.13VersionACCEPTEDFINAL.pdf. Accessed September 9, 2016.

13. National Institute for Health and Care Excellence. Diabetes in Pregnancy: Management from Preconception to the Postnatal Period. NICE clinical guideline NG3. National Collaborating Centre for Women's and Children's Health; London: 2015.

14. Farrar D, Simmonds M, Griffin S, et al. The identification and treatment of women with hyperglycaemia in pregnancy: an analysis of individual participant data, systematic reviews, meta-analyses, and an economic evaluation HTA. In press.

15. American Diabetes Association. Standards of medical care in diabetes - 2014. Diabetes Care. 2014;37(suppl 1):S14-S80.

16. National Institute for Health and Care Excellence. Diabetes in Pregnancy: Management of Diabetes and Its Complications from Preconception to the Postnatal Period. London: National collaborating centre for Women's and Children's Health; 2015.

17. World Health Organization. Diagnostic Criteria and Classification of Hyperglycaemia First Detected in Pregnancy. Geneva: WHO; 2013.

18. Hod M, Kapur A, Sacks DA, et al. The International Federation of Gynecology and Obstetrics (FIGO) initiative on gestational diabetes mellitus: a pragmatic guide for diagnosis, management, and care. Int $J$ Gynecol Obstet. 2015;131(suppl 3):S173-S211.

19. International Association of Diabetes and Pregnancy Study Groups Consensus Panel. International association of diabetes and pregnancy study groups recommendations on the diagnosis and classification of hyperglycemia in pregnancy. Diabetes Care. 2010;33(7):676-682.

20. Tieu J, Middleton P, McPhee A, Crowther C. Screening and subsequent management for gestational diabetes for improving maternal and infant health. Cochrane Database Syst Rev. 2010;(7):CD007222.

21. HAPO; Metzger BE, Lowe LP, Dyer AR, et al. Hyperglycemia and adverse pregnancy outcomes. N Engl J Med. 2008;358(19):1991-2002.

22. Carpenter MW, Coustan DR. Criteria for screening tests for gestational diabetes. Am J Obstet Gynecol. 1982;144(7):768-773.

23. Crowther CA, Hiller JE, Moss JR, et al; Australian Carbohydrate Intolerance Study in Pregnant Women (ACHOIS) Trial Group. Effect of treatment of gestational diabetes mellitus on pregnancy outcomes. N Engl J Med. 2005;352(24):2477-2486.

24. Landon MB, Spong CY, Thom E, et al; Eunice Kennedy Shriver National Institute of Child Health and Human Development MaternalFetal Medicine Units Network. A multicenter, randomized trial of treatment for mild gestational diabetes. $N$ Engl J Med. 2009;361(14): 1339-1348.

25. Bain E, Middleton P, Crowther CA. Progressing towards standard outcomes in gestational diabetes Cochrane reviews and randomised trials. Aust N Z J Obstet Gynaecol. 2016;56(1):113-116.

26. Guariguata L, Linnenkamp U, Beagley J, Whiting DR, Cho NH. Global estimates of the prevalence of hyperglycaemia in pregnancy. Diabetes Res Clin Pract. 2014;103(2):176-185.

27. Carolan M, Gill GK, Steele C. Women's experiences of factors that facilitate or inhibit gestational diabetes self-management. $B M C$ Pregnancy Childbirth. 2012;12(1):1-12.

28. Rowan JA, Hague WM, Gao W, Battin MR, Moore MP; MiG Trial Investigators. Metformin versus insulin for the treatment of gestational diabetes. N Engl J Med. 2008;358(19):2003-2015.

29. Spaulonci CP, Bernardes LS, Trindade TC, Zugaib M, Francisco RPV. Randomized trial of metformin vs insulin in the management of gestational diabetes. Am J Obstet Gynecol. 2013;209(1):e1-e7.

30. Niromanesh S, Alavi A, Sharbaf FR, Amjadi N, Moosavi S, Akbari S. Metformin compared with insulin in the management of gestational diabetes mellitus: a randomized clinical trial. Diabetes Res Clin Pract. 2012;98(3):422-429.

31. Ijäs $\mathrm{H}$, Vääräsmäki $\mathrm{M}$, Morin-Papunen $\mathrm{L}$, et al. Metformin should be considered in the treatment of gestational diabetes: a prospective randomised study. BJOG. 2011;118(7):880-885. 
32. Ainuddin J, Karim N, Hasan AA, Naqvi SA. Metformin versus insulin treatment in gestational diabetes in pregnancy in a developing country. A randomized control trial. Diabetes Res Clin Pract. 2015;107(2):290-299.

33. Hassan JA, Karim N, Sheikh Z. Metformin prevents macrosomia and neonatal morbidity in gestational diabetes. PakJ Med Sci. 2012;28(3): 384-389.

34. Balsells M, García-Patterson A, Solà I, Roqué M, Gich I, Corcoy R. Glibenclamide, Metformin, and Insulin for the Treatment of Gestational Diabetes: A Systematic Review and Meta-Analysis. BMJ [Journal Article]; 2015 [cited January 21, 2015]. Available from: http://www.bmj. com/content/bmj/350/bmj.h102.full.pdf. Accessed September 9, 2016.

35. Horvath K, Koch K, Jeitler K, et al. Effects of treatment in women with gestational diabetes mellitus: systematic review and meta-analysis. BMJ. 2010;340:c1395.

36. Kim C, Newton K, Knopp RH. Gestational diabetes and the incidence of type 2 diabetes: a systematic review. Diabetes Care. 2002;25(10): 1862-1868.

37. Kim C, McEwen LN, Piette JD, Goewey J, Ferrara A, Walker EA. Risk perception for diabetes among women with histories of gestational diabetes mellitus. Diabetes Care. 2007;30(9):2281-2286.

38. McClean S, Farrar D, Kelly CA, Tuffnell D, Whitlaw D. The importance of glucose tolerance testing after pregnancies complicated by gestational diabetes. Diabet Med. 2010;27:650-654.

39. Holt RIG, Coleman MA, McCance DR. The implications of the new International Association of Diabetes and Pregnancy Study Groups (IADPSG) diagnostic criteria for gestational diabetes. Diabet Med. 2011;28(4): 382-385.

40. Gregory R, Swinn RA, Wareham N, et al. An audit of a comprehensive screening programme for diabetes in pregnancy. Prac Diabetes Int. 1998; 15(2):45-48.

41. Kim C, Tabaei BP, Burke R, et al. Missed opportunities for type 2 diabetes mellitus screening among women with a history of gestational diabetes mellitus. Am J Public Health . 2006;96(9):1643-1648.

42. Poston L, Bell R, Croker H, et al; UPBEAT Trial Consortium. Effect of a behavioural intervention in obese pregnant women (the UPBEAT study): a multicentre, randomised controlled trial. Lancet Diabetes Endocrinol. 2015;3(10):767-777.

43. Chiswick C, Reynolds RM, Denison F, et al. Effect of metformin on maternal and fetal outcomes in obese pregnant women (EMPOWaR): a randomised, double-blind, placebo-controlled trial. Lancet Diabetes Endocrinol. 2015;3(10):778-786.

44. Knowler WC, Barrett-Connor E, Fowler SE, et al; Diabetes Prevention Program Research Group. Reduction in the incidence of type 2 diabetes with lifestyle intervention or metformin. N Engl J Med. 2002;346(6): 393-403.

45. National Institute for Health and Care Excellence. Type 2 diabetes: prevention in people at high risk. NICE Clinical Guideline ph38. National Collaborating Centre for Women's and Children's Health; London: 2012 .
46. World Health Organization. Definition, Diagnosis and Classification of Diabetes Mellitus and Its Complications. Report of a WHO Consultation. Part 1: Diagnosis and Classification of Diabetes Mellitus. Geneva: WHO; 1999.

47. American Diabetes Association. Diagnosis and classification of diabetes mellitus. Diabetes Care. 2006;29(suppl 1):S43-S48.

48. Hoffman L, Nolan C, Wilson J, Oats J, Simmons D. Gestational diabetes mellitus - management guidelines. The Australasian Diabetes in Pregnancy Society. Med J Aust. 1998;169(2):93-97.

49. O'Sullivan JB, Mahan CM. Criteria for the oral glucose tolerance test in pregnancy. Diabetes. 1964;13:278-285.

50. Ali FM, Farah N, O’Dwyer V, O’Connor C, Kennelly MM, Turner MJ. The impact of new national guidelines on screening for gestational diabetes mellitus. Ir Med J. 2013;106(2):57-59.

51. Dornhorst A, Paterson CM, Nicholls JS, et al. High prevalence of gestational diabetes in women from ethnic minority groups. Diabet Med. 1992;9(9):820-825

52. Griffin ME, Coffey M, Johnson H, et al. Universal vs. risk factor-based screening for gestational diabetes mellitus: detection rates, gestation at diagnosis and outcome. Diabet Med. 2000;17(1):26-32.

53. Janghorbani M, Stenhouse E, Jones RB, Millward A. Gestational diabetes mellitus in Plymouth, UK - prevalence, seasonal variation and associated factors. J Reprod Med. 2006;51(2):128-134.

54. Khalifeh A, Breathnach F, Coulter-Smith S, Robson M, Fitzpatrick C, Malone F. Changing trends in diabetes mellitus in pregnancy. J Obstet Gynaecol. 2014;34(2):135-137.

55. Koukkou E, Taub N, Jackson P, Metcalfe G, Cameron M, Lowy C. Difference in prevalence of gestational diabetes and perinatal outcome in an innercity multiethnic London population. Eur J Obstet Gynecol Reprod Biol. 1995;59(2):153-157.

56. Makgoba M, Savvidou MD, Steer PJ. An analysis of the interrelationship between maternal age, body mass index and racial origin in the development of gestational diabetes mellitus. BJOG. 2012;119(3): 276-282.

57. Sacks DA, Hadden DR, Maresh M, et al; HAPO Study Cooperative Research Group. Frequency of gestational diabetes mellitus at collaborating centers based on IADPSG consensus panel-recommended criteria: the Hyperglycemia and Adverse Pregnancy Outcome (HAPO) Study. Diabetes Care. 2012;35(3):526-528

58. Samanta A, Burden ML, Burden AC, Jones GR. Glucose tolerance during pregnancy in Asian women. Diabetes Res Clin Pract. 1989;7(2): $127-135$.
International Journal of Women's Health

\section{Publish your work in this journal}

The International Journal of Women's Health is an international, peerreviewed open-access journal publishing original research, reports, editorials, reviews and commentaries on all aspects of women's healthcare including gynecology, obstetrics, and breast cancer. The manuscript management system is completely online and includes

\section{Dovepress}

a very quick and fair peer-review system, which is all easy to use. Visit http://www.dovepress.com/testimonials.php to read real quotes from published authors. 